\title{
Respiratory pathogen colonisation of dental plaque, the lower airways and endotracheal tube biofilms during mechanical ventilation
}

Kirsty M Sands ${ }^{a}$, Melanie J Wilson ${ }^{a}$, Michael A O Lewis ${ }^{a}$ Matt $P$ Wise ${ }^{b}$ Nicki Palmer $^{b}$, Anthony J Hayes ${ }^{c}$, Rosemary A Barnes ${ }^{d}$ and David W Williams ${ }^{a}$

a Oral and Biomedical Sciences, School of Dentistry, Cardiff University, Wales, UK

${ }^{\mathrm{b}}$ Adult Critical Care, University Hospital of Wales, Heath Park, Cardiff, Wales, UK

${ }^{\mathrm{C}}$ Bioimaging Hub, School of Biosciences, Cardiff University, Wales, UK

${ }^{\mathrm{d}}$ Cardiff Institute of Infection \& Immunity, School of Medicine, Heath Park, Cardiff, Wales, UK

Corresponding Author's details:

Kirsty M Sands, Sandsk1@cf.ac.uk, $5^{\text {th }}$ Floor, Oral and Biomedical Sciences, School of Dentistry, Cardiff University, Heath Park, Cardiff, Wales, CF14 4XY

Keywords: mechanical ventilation, Staphylococcus aureus, Pseudomonas aeruginosa, endotracheal tube and ventilator associated pneumonia.

\begin{abstract}
:
Purpose: In mechanically ventilated patients, the endotracheal tube is an essential interface between the patient and ventilator, but inadvertently it also facilitates the development of ventilator-associated pneumonia (VAP) by subverting pulmonary host defense. A number of investigations suggest that bacteria colonising the oral cavity may be important in the aetiology of VAP. The present study evaluated microbial changes that occurred in dental plaque and lower airways of 107 critically ill mechanically ventilated patients. Materials and Methods: Dental plaque and lower airways fluid was collected during the course of mechanical ventilation, with additional samples of dental plaque obtained during the entirety of patients' hospital stay. Results: A 'microbial shift' occurred in dental plaque, with colonisation by potential VAP pathogens, namely, Staphylococcus aureus and Pseudomonas aeruginosa in 35 patients. Post-extubation analyses revealed that $70 \%$ and $55 \%$ of patients whose dental plaque included $S$. aureus and $P$. aeruginosa, respectively, reverted back to having a predominantly normal oral microbiota. Respiratory pathogens were also isolates from the lower airways and within the endotracheal tube biofilms. Conclusions: To the best of our knowledge, this is the largest study to date exploring oral microbial changes during both mechanical ventilation and following recovery from critical illness. Based on these findings, it was apparent that during mechanical ventilation, dental plaque represents a source of potential VAP pathogens.
\end{abstract}




\section{Introduction}

In mechanically ventilated patients the endotracheal tube is an essential interface between the lungs and the ventilator. Unfortunately, the presence of an endotracheal tube also impairs pulmonary host defenses and promotes ventilator-associated pneumonia (VAP) through supporting biofilm formation within its inner lumen [1,2]. In addition, the endotracheal tube and incomplete mouth closing will alter the oral microenvironment. VAP is the most common nosocomial infection in critical care with a prevalence of approximately $15 \%$ and prognosis is negatively influenced with involvement of multidrug resistant pathogen biofilms [3,4]. The endotracheal tube biofilm may serve as a reservoir of respiratory pathogens that are largely protected from host defense mechanisms. In recent years, studies into the origin of VAP causing microorganisms have primarily focused on oropharyngeal sites rather than the gastro-intestinal tract [5-8]. As a consequence, a number of recent strategies aimed at preventing VAP have sought to target the oral microbiome $[9,10]$.

Dental plaque was initially considered to be a bacterial construct (i.e. a biofilm) in the 1970s [11]. Dental plaque harbors an estimated 500 different bacterial species with variation in microbial composition occurring between and along the teeth [12]. Streptococcus species are recognised as primary pioneer colonisers of teeth and are initiators of dental plaque development [13]. Lazarevic et al. analysed the oral microbiome using molecular methods and reported that up to $70 \%$ of sequences belonged to the Streptococcus and Neisseria genera [14]. Saliva plays an important role in modulating dental plaque formation $[15,16]$. Glycoproteins and proline-rich proteins (PRPs) in saliva will adsorb to tooth surfaces generating an enamel pellicle allowing bacteria to adhere [17].

The oral microbiome could promote VAP in several ways [18]. Firstly, during mechanical ventilation rapid colonisation by potential respiratory pathogens including Pseudomonas, Klebsiella, Staphylococcus aureus and Acinetobacter can occur and these bacteria may subsequently disseminate to the lung $[8,19,20]$. Secondly, commensal oral bacteria may actively promote 
respiratory pathogen colonisation of the endotracheal lumen, and these bacteria may again translocate to the lower airways leading to VAP [1,21]. Biofilm-mediated infections are difficult to treat, as not only are the cells protected within the biofilm structure, but the microorganisms involved are also frequently inherently less susceptible to antimicrobial agents [22-24].

Colonisation of dental plaque by respiratory pathogens is important in VAP aetiology, and it is also known that for the majority of critically ill patients, oral hygiene frequently deteriorates during mechanical ventilation [25,26]. Furthermore, not all oral hygiene interventions appear effective at reducing VAP incidence $[27,28]$ and a recent meta-analysis even suggested that accepted oral hygiene treatments, such as use of chlorhexidine may actually lead to harmful effects [29].

In order to deliver effective oral care to critically ill patients to reduce VAP, it is important to increase our understanding of the dynamics of the oral microbiome during mechanical ventilation and how this relates to contamination of both the ETT and lower airway. The current study examined the nature of microbial changes in dental plaque and the lower airway, during mechanical ventilation and, in contrast to previous studies, during the patient recovery after mechanical ventilation.

\section{Materials and Methods}

\section{Methods}

\section{Patient recruitment}

Ethical approval was obtained from the National Research Ethics Service (NRES) within the Research Ethics Committee (REC) for Wales (Ref: 13/WA/0039). In order for sufficient statistical power (>80\%) to observe a $20 \%$ change in at least one phylum in microbial profiles and associated 
downstream high-throughput techniques [30], the minimum number of participants required for the study was 101 . Mechanically ventilated patients were eligible for inclusion in the study if they were aged $>18$ years, had $>8$ original teeth, their anticipated period of mechanical ventilation was $>24 \mathrm{~h}$ and their expected survival was $>24 \mathrm{~h}$. Informed consent for participation in the study was obtained from the next of kin and also taken from the patient if they recovered capacity.

Within 6h of critical care admission, a critical care mouth plan was completed to determine the level and frequency of oral care required. Oral care included toothbrushing 4 times a day with sterile water, moistening of the oral cavity and lips. Antiseptic mouthwashes were not used. Additional care was provided for denture wearers. VAP was diagnosed using the existing Patients with a clinical suspicion of VAP had a Clinical Pulmonary Infection Score (CPIS) calculated using parameters of temperature, white blood cell count, $\mathrm{PaO}_{2} / \mathrm{FIO}_{2}$ ratio, the presence of tracheal secretions and changes on chest radiograph. Quantitative microbiological culture $\left(>10^{3} \mathrm{CFU} / \mathrm{ml}\right)$ of the lower airways by (bronchoalveolar lavage (BAL)/non-directed bronchoalveolar lavage (NBL) was undertaken if the CPIS score was $>6 B A L$ was performed bronchoscopically by an attending clinician, whilst NBLs were undertaken by the bedside nurse inserting a suction catheter through the catheter mount into the lung parenchyma and flushing and withdrawing sterile saline [32-36].

\section{Decayed, missing and filled teeth (DMFT) score}

The DMFT score was recorded (by a dental professional). The DMFT score is a measurement of dental caries status and is therefore an indicator of prior longer-term oral hygiene levels [31]. Each incidence of a tooth recorded as decayed, missing or filled results in a score of 1 to generate a score of 0-28, with higher scores representing poor oral health. Final DMFT scores can therefore range between 0-28. DMFT scores, although not reflective of the remaining dentition, may indicate prior differences in oral hygiene 
maintenance within the patient cohort and therefore the level of risk for dental plaque changes.

\section{Dental plaque collection}

Subgingival and supragingival plaque was collected using paper points (QED size 40) and dental examination kits (Minerva Dental) [37]. Collection was performed on 3 occasions during the first week of admission to critical care and then weekly. The fist sample was collected within $24 \mathrm{~h}$ the start of mechanical ventilation. A total of 9 paper points, sampling 3 teeth per area (front, middle and back) were used per collection. In cases where the patient did not have sufficient teeth for the above protocol, plaque was taken from the closest areas. Plaque specimens were suspended in transport medium [38] and processed using microbial culture on the day of collection.

Collection of subglottic aspirations, non-directed bronchoalveolar lavages (NBLs), bronchoalveolar lavages (BALs) and endotracheal tubes (ETTs)

Subglottic secretions were collected through a subglottic port in the ETT using a syringe and transferred into sterile universals. Subglottic aspirates and NBLs were aseptically transferred into universal containers and endotracheal tubes were collected and placed in sterile bags when available for transport to the microbiology laboratory.

\section{Identification of respiratory pathogens}

Clinical specimens were processed within a Class II safety cabinet. Dental plaque was vortex-mixed and spread-plated on to appropriate selective agar media for detection of Staphylococcus aureus (MSB; Mannitol Salt Agar, MSA) and Pseudomonas aeruginosa (Pseudomonas agar base; Lab M), which are prevalent VAP pathogens [39-41]. Agar media were incubated at $37^{\circ} \mathrm{C}$ under aerobic conditions for 5 days.

NBLs and BALs were centrifuged for $3 \mathrm{~min}$ at $10,000 \mathrm{~g}$, and the pellet re-

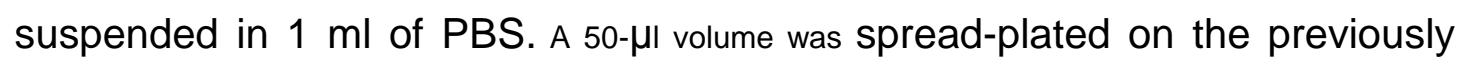
described selective agar. Growth of $P$. aeruginosa and $S$. aureus was 
recorded, and colonies of presumptive respiratory pathogens identified by biochemical testing. Staphylococcus aureus colonies were sub-cultured on MSA agar for $18-24 \mathrm{~h}$ at $37^{\circ} \mathrm{C}$ and tested for catalase and coagulase activity [42]. Colonies of $P$. aeruginosa were sub-cultured on Pseudomonas agar for $18-24 \mathrm{~h}$ at $37^{\circ} \mathrm{C}$ and tested for oxidase activity.

Definitive identification of $S$. aureus and $P$. aeruginosa was by speciesspecific PCR (Table 1) [43,44]. DNA extraction employed a commercially available DNA extraction kit (Qiagen). PCR was performed in a total reaction volume of $50 \mu$ containing $2 \mu$ of DNA template. Thermal cycling parameters for $S$. aureus detection were an initial $5 \mathrm{~min}$ at $94^{\circ} \mathrm{C}$, followed by 35 cycles of $94^{\circ} \mathrm{C}$ for $40 \mathrm{~s}, 50^{\circ} \mathrm{C}$ for $40 \mathrm{~s}$ and $72^{\circ} \mathrm{C}$ for $1 \mathrm{~min}$, with a final elongation step of $72^{\circ} \mathrm{C}$ for $10 \mathrm{~min}$. For $P$. aeruginosa $\mathrm{PCR}$, there was an initial denaturation step of $95^{\circ} \mathrm{C}$ followed by 35 cycles of $94^{\circ} \mathrm{C}$ for $45 \mathrm{~s}, 58.4^{\circ} \mathrm{C}$ for $45 \mathrm{~s}$ and $72^{\circ} \mathrm{C}$ for 1 min ending with 5 min at $72^{\circ} \mathrm{C}$.

\section{Antimicrobial susceptibility profiling}

Staphylococcus aureus and $P$. aeruginosa were cultured on Mueller Hinton agar at $37^{\circ} \mathrm{C}$ for $18-24$ h. A $0.5 \mathrm{McF}$ arland standard $\left(10^{8} \mathrm{cells} / \mathrm{ml}\right)$ was prepared to create an inoculum for antimicrobial sensitivity testing. A sterile swab was used to homogenously inoculate the 0.5 McFarland standard across the agar. Cefoxitin discs were used to identify MRSA, whilst sensitivity profiles of $P$. aeruginosa and $S$. aureus were tested against 6-12 antimicrobials discs (selected based on previous administration to patients and according to frequent antibiotics used for these microorganisms). Agars were incubated for $18-24 \mathrm{~h}$ at $37^{\circ} \mathrm{C}$ and subsequent zones of inhibition (ZOI) measured and categorisation of isolate susceptibility (sensitive, resistant and intermediate resistant) was done according to British Society for Antimicrobial Chemotherapy (BSAC) guidelines. For analysis, the isolate antimicrobial sensitivities were grouped into clinical site origin.

\section{Imaging of endotracheal tube biofilms}

A $0.5-\mathrm{cm}$ section of an ETT was placed in $2 \mathrm{ml}$ of $10 \%(\mathrm{v} / \mathrm{v})$ formalin for $24 \mathrm{~h}$, processed in embedded wax and sectioned to $20 \mu \mathrm{m}$. Peptide nucleic acid 
probes (PNA; $100 \mu \mathrm{mol}$; Panagene; Table 2) were prepared in hybridisation solution (10\% (w/v) dextran sulphate, $10 \mathrm{mM} \mathrm{NaCl}, 30 \%(\mathrm{w} / \mathrm{v})$ formamide, $0.1 \%(\mathrm{w} / \mathrm{v})$ sodium pyrophosphate, $0.2 \%(\mathrm{w} / \mathrm{v})$ polyvinylpyrolidone, $0.2 \%(\mathrm{w} / \mathrm{v})$ ficol, $5 \mathrm{mM}$ disodium EDTA, $50 \mathrm{mM}$ Tris $\mathrm{HCl}$ and $0.2 \%$ Triton- $\mathrm{X}$ at $\mathrm{pH} 7.5$ ) [45].

Processing involved enzymatic pre-treatment to promote access of the biofilm to PNA probe hybridisation. A $50-\mu l$ volume of lysostaphin was added to the section which was incubated at $20^{\circ} \mathrm{C}$ for $30 \mathrm{~min}$. A $100-\mu$ volume of lysozyme $(10 \mathrm{mg} / \mathrm{ml})$ was then added followed by incubation at $37^{\circ} \mathrm{C}$ for $30 \mathrm{~min}$. A $100-$ $\mu l$ volume of PNA probe (300 nM for all probes with exception of the $S$. aureus-specific probe which was at $450 \mathrm{nM}$ ) was added and incubated at $55^{\circ} \mathrm{C}$ for $90 \mathrm{~min}$. Sections were flooded with $2 \mathrm{ml}$ of wash solution (5 mM Tris, $15 \mathrm{mM} \mathrm{NaCl}$ and $1 \%(\mathrm{v} / \mathrm{v})$ Triton $\mathrm{X}-100$ at $\mathrm{pH} 10)$ and incubated at $55^{\circ} \mathrm{C}$ for 15 min [45] prior to mounting under coverslips with Vectashield ${ }^{T M}$ (Vectorlabs). Controls devoid of probe were included.

Sections were imaged using a Leica TCS SP2 AOBS spectral confocal microscope (Leica, Heidelberg, Germany) and appropriate excitation and emission settings for FITC (ex max 494nm; em max 518nm); Cy 3 (ex max 550nm; em max 570nm) and Cy 5 (ex max 650nm; em max 670nm). Micrographs were presented as image overlays of confocal fluorescence (colour) superimposed upon Nomarski differential interference contrast (greyscale).

\section{Statistical analysis}

Where appropriate, statistical analysis (t test sampling) was performed using IBM SPSS v20.

\section{Results}

\section{Patient recruitment and demographics}


A total of 1016 patients were screened over 14 months. Of these, 5 patients were $<18$ years, 20 patients had $<8$ teeth, 210 patients were anticipated to be mechanically ventilated for $<24 \mathrm{~h}, 439$ patients were not mechanically ventilated and 232 patients could not be consented. A total of 107 patients (65 male and 42 female; mean age 54) met the inclusion criteria and were recruited following receipt of informed consent. The median duration of mechanical ventilation was 7 days.

The study was performed in a single adult critical care unit. Patients were recruited with various health backgrounds for admission to critical care. Patient demographics and clinical measurements are presented in table 3.

There was a lower mean age (39 y) for acute/ poly-trauma ( $n=12)$, compared to respiratory failure $(n=30$; mean age of $60 \mathrm{y}$ ). The mean age of patients admitted/receiving mechanical ventilation following an out of hospital cardiac arrest $(\mathrm{OOHCA})$ was 60 y $(\mathrm{n}=11)$. A total of $77(71 \%)$ of mechanically ventilated patients received at least one antibiotic, and just under half of patients (49\%) received $>2$ different antibiotics during the course of mechanical ventilation. Over 30 antibiotics were administered to patients during the clinical study (table 3). Antifungals (including nystatin and fluconazole) were also administered to mechanically ventilated patients $(n=12)$. Of 107 patients, DMFT indices were obtained for 97 and these scores increased with age; a score $>10$ was typically recorded for patients $>40$ years of age.

\section{Microbiological analysis during mechanical ventilation}

A total of 848 dental plaque samples were obtained from 107 mechanically ventilated patients. Of these, 592 were collected during mechanical ventilation, with a mean number of plaque samples of 5 per patient. At least one dental plaque specimen was colonised with either $S$. aureus (43 patients) or $P$. aeruginosa (23 patients) during mechanical ventilation. Co-isolation of $S$. aureus and $P$. aeruginosa occurred for 10 patients. Of 43 patients who were culture positive for $S$. aureus during mechanical ventilation, 21 (48\%) were 
culture negative for $S$. aureus at the time of intubation. A total of 23 patients were culture positive for $P$. aeruginosa during mechanical ventilation, with 18 $(78 \%)$ patients culture negative for this species at the time of intubation (Figure 1). The dental plaque of 35 patients out of 107 (33\%) therefore exhibited a change in microbial composition to incorporate at least one of the targeted respiratory pathogens.

Staphylococcus aureus was detected in the lower airways of 37 patients, and predominately occurred with concurrent dental plaque colonisation. The subglottic secretions of 14 patients and 4 patients contained $S$. aureus and $P$. aeruginosa, respectively. Co-colonisation of $P$. aeruginosa from both dental plaque and lower airway specimens was higher than for $S$. aureus. Twenty nine patients were culture positive for $P$. aeruginosa, and 23 of these were positive from dental plaque culture. ETT biofilm imaging using PNA-CLSM facilitated detection and spatial location of targeted species in the ETT biofilm (Figure 2).

Forty-one patients were clinically diagnosed and treated for VAP during the study. This apparent high VAP rate can be related to the patient cohort as many had prolonged ventilation (13 ventilated between $5-7 \mathrm{~d}$ and 57 ventilated $>7 \mathrm{~d}$ ). Of these patients, 18 had respiratory pathogens within dental plaque during mechanical ventilation, and 24 patients were colonised with the same respiratory pathogen within the dental plaque and the lower airways at any time point. In addition 9 patients clinically treated for VAP had respiratory pathogens in their dental plaque from the start and over the course of mechanical ventilation.

\section{Antimicrobial sensitivity of $\boldsymbol{S}$. aureus and $\boldsymbol{P}$. aeruginosa isolates}

The majority $(>70 \%)$ of tested isolates from all sites were susceptible to the antibiotics tested. A total of 114 isolates of $S$. aureus (table 4 ) were recovered both during mechanical ventilation and into the recovery period. Where differences were observed in sensitivities, $S$. aureus isolates with antibiotic resistance profiles were most frequently isolated from subglottic secretions 
and tended to more frequently exhibit resistance to erythromycin, penicillin and cefepime. The majority of $S$. aureus were sensitive to cefoxitin and ceftazidime irrespective of origin. Of the $56 P$. aeruginosa isolates, 35 were from dental plaque. Antimicrobial resistance patterns for all tested antibiotics ranges between $2 \%$ (ciprofloxacin) to $23 \%$ of strains (meropenem) (table 5 ). Although only $5 \mathrm{P}$. aeruginosa isolates were recovered from endotracheal tube sections and one of these exhibited the most resistant profile across all antibiotics tested. P. aeruginosa isolates exhibited the greatest sensitivity to Tobramycin with antibiotic susceptibilities ranging from $80 \%$ of isolates sensitive to all antimicrobials in the ETTs, to $97.1 \%$ in the dental plaque.

Antimicrobial sensitivity patterns for recovered isolates of $P$. aeruginosa between dental plaque, the lower airways and endotracheal tube biofilms were largely similar for 7 out of 10 patients. Similarly, for recovered isolates of $S$. aureus between dental plaque, the lower airways and endotracheal tube biofilms, antimicrobial sensitivity patterns were related for 21 out of 30 patients. (All individual isolate sensitivities are shown within the supplementary material).

In the context of this study, an MDR pathogen was defined as a pathogen exhibiting a resistant profile (In terms of $\mathrm{ZOI}$ according to BSAC guidelines) to at least three antibiotics. A total of 3 patients were colonized with MDR $P$. aeruginosa and 21 patients were colonized with an MDR $S$. aureus (8 patients colonized with MRSA as detected by resistance to cefoxitin with a ZOI $<20 \mathrm{~mm}$ ).

\section{Dental plaque analysis after endotracheal tube extubation}

A total of 256 dental plaque samples were collected during the recovery period with 88 collected within 1 week post-endotracheal tube extubation, 66 during week 2 post-extubation, 43 collected 3 weeks post-extubation and a further 59 were collected $>1$ month post-extubation. For a total of 31 patients, dental plaque was not collected due to either patient withdrawal upon recovery, or death. Out of the 35 patients that exhibited microbial changes 
during mechanical ventilation, analysis of post-extubation dental plaque was completed for 27 patients.

These analyses allowed an assessment of persistence of respiratory pathogens in patients' dental plaque. In patients where dental plaque was colonised with $S$. aureus, $71 \%$ reverted back to a predominantly normal oral microbiota, devoid of $S$. aureus colonisation after extubation. Similarly for patients whose plaque was colonised by $P$. aeruginosa, 55\% became culture negative for $P$. aeruginosa after extubation. A bar graph (Figure 1) compares the colonisation of respiratory pathogens during mechanical ventilation and the recovery period, highlighting reversed-microbial changes during the recovery period. Readmission rates to critical care were similar for patients exhibiting a reverse-microbial change (11.1\%) and those patients harboring pathogens within their dental plaque during the recovery period $(10 \%)$.

\section{Discussion}

VAP is an important hospital acquired infection in critically ill patients [4] and is associated with increased mortality, duration of stay and cost [46]. Prevention of VAP is vital, and an important facet in the development of appropriate preventative strategies is a better understanding of the aetiology and pathogenesis of VAP $[47,48]$.

The microbiome of the oral cavity is both highly diverse and dynamic, primarily because of the wide range of microbial habitats that exist in the mouth and the fluctuations that can arise in these environments due to changes in diet, salivary flow and oral hygiene interventions [49-54]. Unsurprisingly, since the oral cavity is directly linked to the lower airways, associations between oral microbiology and respiratory infections are frequently made. In the case of VAP, it has been suggested that oral microorganisms could promote colonisation of dental plaque and endotracheal biofilms by potential respiratory pathogens, or may directly cause VAP themselves [55]. Carrilho-Neto et al, showed a reduction in oral hygiene for the majority of hospitalized patients, reporting a positive correlation between dental plaque index and gingival index [56]. Gingival 
inflammation caused by poor oral hygiene in intubated patients may also drive inflammation within the lungs [56-58]. The primary objective of this study was to determine the colonisation dynamics for key microbial species at defined sites in critically ill patients undergoing mechanical ventilation. Although previous studies have examined colonisation with potential respiratory pathogens following critical illness, this has only been over a short duration of ventilation following intubation.

An important finding of this study was that the composition of dental plaque in a significant proportion (approximately one third) of mechanically ventilated patients altered with inclusion of the potential respiratory pathogens $S$. aureus and $P$. aeruginosa. Importantly, these bacterial species may exhibit resistance to antibiotics, and are causative agents in up to $50 \%$ of VAP cases [39-41]. The presence of these targeted microorganisms in the endotracheal tube was also evident using the culture independent tool of PNA-FISH coupled with CLSM. Aggregates of respiratory pathogens were clearly evident using this approach. The displacement of respiratory pathogens to the lower airway would deliver infectious agents already within a biofilm phenotype and are therefore more resistant to host defence mechanisms and administered antimicrobials. Although only a small proportion of $S$. aureus isolates were reported as MRSA, $\sim 25 \%$ isolates recovered from dental plaque were resistant to at least one antibiotic tested in vitro (tables 4 and 5.) When assessing antimicrobial resistant levels between isolates recovered within the dental plaque and the lower airways, the highest levels of resistance were recovered from outside of the oral cavity. Resistance rates were highest for $P$. aeruginosa within the ETT biofilm, and for $S$. aureus within subglottic secretions (table 4). This can imply higher rates of resistance within the airways, and if VAP were to develop in these patients then this could exacerbate the success of antimicrobial therapy.

Importantly, in the majority of patients where microbial changes occurred in the dental plaque, a reversal occurred once the patient was extubated, and this was most readily evident with $S$. aureus colonisation. A higher proportion of patients colonised with $P$. aeruginosa retained the respiratory pathogen 
colonisation post extubation. Although most dental plaque communities reverted back to a phenotype without target respiratory pathogens within one week of extubation, the fact that some patients remained colonised with respiratory pathogens over a prolonged duration could represent a patient group at risk of subsequent hospital-acquired pneumonia.

Although not regarded as a normal inhabitant of the oral cavity, $S$. aureus has been detected within the dental plaque of debilitated or elderly individuals [59]. An observational study of hospitalized patients by Sachdev et al, $(62 \%$ were not ventilated), revealed colonization rates of $S$. aureus at $\sim 14 \%$ [26]. In the current study, the high incidence (43 of 107 patients) of $S$. aureus in dental plaque was nevertheless surprising, particularly as half of these patients did not have $S$. aureus in their dental plaque at the time of intubation. Similarly, dental plaque also became colonised with $P$. aeruginosa during mechanical ventilation, albeit at a lower incidence. As dental plaque is easily sampled, and is a less invasive procedure than a NBL or BAL, isolation of potential respiratory pathogens in dental plaque of patients with suspected VAP may enable targeted antimicrobial therapy and should be evaluated in future studies. In 6 mechanically ventilated patients, although $P$. aeruginosa was isolated within the lower airways there was no confirmation of $P$. aeruginosa via microbial culture within their dental plaque. Perhaps further investigation coupled with high-throughput technologies could elucidate whether $P$. aeruginosa could be detected if present in a much lower abundance. Furthermore, there is the potential for dental plaque analysis in guiding empiric therapy, however false negatives when relating to the occurrence of respiratory pathogens in the lower airways can occur.

One of the main limitations of the current study is that target pathogens were limited to $S$. aureus and $P$. aeruginosa by culture specific methods. Whilst additional respiratory pathogens were not assessed in this study, others have found that E. coli, Klebsiella species and Acinetobacter species may also colonise dental plaque and endotracheal tubes during mechanical ventilation [2]. Furthermore we have demonstrated considerable microbial diversity and colonisation of plaque with potentially pathogenic bacteria using non-culture 
techniques such as community profiling by high throughput sequencing [30]. The reason(s) why such microbial changes occur in dental plaque remain unclear, but are likely linked to local environmental changes in the mouth. These may include plaque accumulation and gingival inflammation from inadequate delivery of oral care during mechanical ventilation, perturbations of salivary composition and reduced salivary flow as a consequence of incomplete mouth closure, or following receipt of drugs [60].

This is to our knowledge, the first study in critically ill mechanically ventilated patients that has sequentially assessed the dental microflora over a prolonged duration and shown a decrease in respiratory pathogen colonisation of dental plaque in some patients during recovery from critical illness. Once elucidated, the reasons why the dental plaque of some patients' begins to revert back to a profile of microbes without respiratory pathogens (identified during mechanical ventilation), potentially offers new preventative strategies for VAP. Whether those patients who have persistent colonisation with respiratory pathogens despite recovery from critical illness are at increased risk of hospital acquired infection needs to be evaluated in larger adequately powered studies. It was evident from this present study that microbial changes occur in the dental plaque of mechanically ventilated patients and these include colonisation by respiratory pathogens. The presence of respiratory pathogens in dental plaque is a risk factor for VAP. Emphasising the importance of maintaining oral hygiene during mechanical ventilation, may actually limit this reservoir of respiratory pathogens within the dental plaque of mechanically ventilated patients.

\section{Acknowledgments}

We gratefully acknowledge the research unit within critical care at The University Hospital of Wales, Cardiff for their continued support. We thank Mrs. Kath Allsopp and Mr. Marc Isaccs for the processing of endotracheal tube biofilms for microscopic analysis. 


\section{References}

[1] Cairns S, Thomas JG, Hooper SJ, Wise MP, Frost PJ, Wilson MJ, Lewis MA, Williams DW. Molecular analysis of microbial communities in endotracheal tube biofilms. PLoS One 2011; 6:e14759.

[2] Gil-Perotin S, Ramirez P, Marti V, Sahuquillo JM, Gonzalez E, Calleja I, Menendez R, Bonastre J. Implications of endotracheal tube biofilm in ventilator-associated pneumonia response: a state of concept. Crit Care 2012; 16:R93.

[3] Branch-Elliman W, Wright SB, Howell MD. Determining the ideal strategy for ventilator-associated pneumonia prevention: cost-benefit analysis. Am J Respir Crit Care Med. 2015; 192:57-63.

[4] Kollef $\mathrm{MH}$. Ventilator-associated pneumonia prevention is it worth it? Am J Respir Crit Care Med. 2015; 192:5-7.

[5] Bahrani-Mougeot FK, Paster BJ, Coleman S, Barbuto S, Brennan MT, Noll J, Kennedy T, Fox PC, Lockhart PB. Molecular analysis of oral and respiratory bacterial species associated with ventilator-associated pneumonia. J Clin Microbiol 2007; 45:1588-93.

[6] Bonten MJM, Gaillard CA, van Tiel F, Smeets HGW, van der Geest S, Stobberingh EE. The stomach is not a source for colonization of the upper respiratory tract and pneumonia in ICU patients. Chest 1994; 105:878-84.

[7] Garrouste-Orgeas M, Chevret S, Arlet G, Marie O, Rouveau M, Popoff $\mathrm{N}$, et al. Oropharyngeal or gastric colonization and nosocomial pneumonia in adult intensive care unit patients. A prospective study based on genomic DNA analysis. Am J Respir Crit Care Med 1997; 156:1647-55.

[8] Heo SM, Haase EM, Lesse AJ, Gill SR, Scannapieco FA. Genetic relationships between respiratory pathogens isolated from dental plaque and 
bronchoalveolar lavage fluid from patients in the intensive care unit undergoing mechanical ventilation. Clin Infect Dis 2008; 47:1562-70.

[9] Silvestri L1, Weir I, Gregori D, Taylor N, Zandstra D, Van Saene JJ, Van Saene HK. Effectiveness of oral chlorhexidine on nosocomial pneumonia, causative microorganisms and mortality in critically ill patients: a systematic review and meta-analysis. Minerva Anestesiol 2014; 80:805-20.

[10] Shi Z, Xie H, Wang P, Zhang Q, Wu Y, Chen E, Ng L, Worthington HV, Needleman I, Furness $S$. Oral hygiene care for critically ill patients to prevent ventilator-associated pneumonia. Cochrane Database Syst Rev 2013; 13:CD008367.

[11] Costerton JW, Geesey GG, Cheng K-J. How bacteria stick. Sci Am. 1978; 238:86-95.

[12] Rosan B, Lamont RJ. 2000. Dental plaque formation. Microbes Infect 2000; 2:1599-607.

[13] Denepitiya L, Kleinberg I. A comparison of the microbial compositions of pooled human dental plaque and salivary sediment. Arch Oral Biol 1982; 27:739-45.

[14] Lazarevic V, Whiteson K, Huse S, Hernandez D, Farinelli L, Osterås M, Schrenzel J, François P.. Metagenomic study of the oral microbiota by Illumina high-throughput sequencing. J Microbiol Methods 2009; 79:266-71.

[15] Rudney JD, Krig MA, Neuvar EK. Longitudinal study of relations between human salivary antimicrobial proteins and measures of dental plaque accumulation and composition. Arch Oral Biol. 1993; 38:377-86.

[16] Rudney JD. 2000. Saliva and dental plaque. Adv Dent Res. 2000; 14:29-39. 
[17] Kolenbrander PE, Egland PG, Diaz PI, Palmer RJ Jr. Genome-genome interactions: bacterial communities in initial dental plaque. Trends Microbiol. 2005; 13:11-5.

[18] Gomes-Filho IS, Passos JS, Seixas da Cruz S. Respiratory disease and the role of oral bacteria. J Oral Microbiol 2010; 2:1-6.

[19] Scannapieco FA, Yu J, Raghavendran K, Vacanti A, Owens SI, Wood $\mathrm{K}$, Mylotte JM. A randomized trial of chlorhexidine gluconate on oral bacterial pathogens in mechanically ventilated patients. Crit Care 2009; 13:R117.

[20] Scannapieco FA, Stewart E, Mylotte J. Colonization of dental plaque by respiratory pathogens in medical intensive care patients. Crit Care Med 1992; 20:740-5.

[21] Perkins SD, Woeltje KF, Angenent LT. Endotracheal tube biofilm inoculation of oral flora and subsequent colonization of opportunistic pathogens. Int J Med Microbiol 2010; 300:503-11.

[22] Ma L1, Conover M, Lu H, Parsek MR, Bayles K, Wozniak DJ. Assembly and development of the Pseudomonas aeruginosa biofilm matrix. PLoS Pathog 2009; 5:e1000354.

[23] Kim J, Hegde M, Kim SH, Wood TK, Jayaraman A. A microfluidic device for high throughput bacterial biofilm studies. Lab Chip. 2012; 12:115763.

[24] Muszanska AK, Nejadnik MR, Chen $Y$, van den Heuvel ER, Busscher $\mathrm{HJ}$, van der Mei HC, Norde W. Bacterial adhesion forces with substratum surfaces and the susceptibility of biofilms to antibiotics. Antimicrob Agents Chemother. 2012; 56:4961-4.

[25] Fourrier F, Duvivier B, Boutigny $H$, Roussel-Delvallez M, Chopin C. Colonization of dental plaque: a source of nosocomial infections in intensive care unit patients. Crit Care Med 1998; 26:301-8. 
[26] Sachdev M, Ready D, Brealey D, Ryu J, Bercades G, Nagle J, BorjaBoluda S, Agudo E, Petrie A, Suvan J, Donos N, Singer M, Needleman I. Changes in dental plaque following hospitalisation in a critical care unit: an observational study. Crit Care 2013; 17:R189.

[27] Alhazzani W, Smith O, Muscedere J, Medd J, Cook D. Toothbrushing for critically ill mechanically ventilated patients: a systematic review and metaanalysis of randomized trials evaluating ventilator-associated pneumonia. Crit Care Med; 41:646-55.

[28] Gu W-J, Gong Y-Z, Pan L, Ni Y-X, Liu J-C. Impact of oral care with versus without toothbrushing on the prevention of ventilator-associated pneumonia: a systematic review and meta-analysis of randomized controlled trials. Crit Care 2012; 16:R190.

[29] Klompas M, Speck K, Howell MD, Greene LR, Berenholtz SM. Reappraisal of routine oral care with chlorhexidine gluconate for patients receiving mechanical ventilation: systematic review and meta-analysis. JAMA Intern Med 2014; 02215:1-11.

[30] Sands KM, Twigg JA, Lewis MA, Wise MP, Marchesi JR, Smith A, Wilson MJ, Williams DW. Microbial profiling of dental plaque from mechanically ventilated patients. J Med Microbiol 2016; 65:147-59.

[31] Becker T, Levin L, Shochat, T, Einy S. How much does the DMFT index underestimate the need for restorative care? J Dent Educ 2007; 71:677-81.

[32] Estella A, Álvarez-Lerma F. Should the diagnosis of ventilator associated pneumonia be improved? Med Intensiva. 2011; 35:578-82.

[33] Hellyer TP, Morris AC, McAuley DF, Walsh TS, Anderson NH, Singh S, Dark P, Roy AI, Baudouin SV, Wright SE, Perkins GD, Kefala K, Jeffels M, McMullan R, O'Kane CM, Spencer C, Laha S, Robin N, Gossain S, Gould K, 
Ruchaud-Sparagano MH, Scott J, Browne EM, MacFarlane JG, Wiscombe S, Widdrington JD, Dimmick I, Laurenson IF, Nauwelaers F, Simpson AJ. Diagnostic accuracy of pulmonary host inflammatory mediators in the exclusion of ventilator-acquired pneumonia. Thorax 2015; 70:41-7

[34] Kalanuria AA, Zai W, Mirski M. Ventilator-associated pneumonia in the ICU. Crit Care 2014; 18:208

[35] Pugin J, Auckenthaler R, Mili N, Janssens JP, Lew PD, Suter PM. Diagnosis of ventilator-associated pneumonia by bacteriologic analysis of bronchoscopic and nonbronchoscopic "blind" bronchoalveolar lavage fluid. Am Rev Respir Dis. 1991; 143:1121-9.

[36] Zilberberg MD, Shorr AF. Ventilator-associated pneumonia: the clinical pulmonary infection score as a surrogate for diagnostics and outcome. Clin Infect Dis 2010; 51:S131-5

[37] Bollen CM, Quirynen M. Specimen collection in dental plaque and oral microbiology. Rev Belge Med Dent (1984) 1994; 49:44-51.

[38] Syed SA, Loesche WJ. Survival of human dental plaque flora in various transport media. Appl Microbiol 1972; 24:638-44.

[39] Parker CM, Kutsogiannis J, Muscedere J, Cook D, Dodek P, Day AG, Heyland DK; Canadian Critical Care Trials Group. Ventilator-associated pneumonia caused by multidrug-resistant organisms or Pseudomonas aeruginosa: prevalence, incidence, risk factors, and outcomes. J Crit Care. 2008; 23:18-26.

[40] Bouza E, Giannella M, Bunsow E, Torres MV, Granda MJ, MartínRabadán P, Muñoz P; Gregorio Marañón Task Force for Pneumonia (GANG). Ventilator-associated pneumonia due to meticillin-resistant Staphylococcus aureus: risk factors and outcome in a large general hospital. J Hosp Infect. 2012; 80:150-5. 
[41] Smith AJ, Jackson MS, Bagg J. The ecology of Staphylococcus species in the oral cavity. J Med Microbiol 2001; 50:940-6.

[42] Vandecandelaere I, Matthijs N, Van Nieuwerburgh F, Deforce D, Vosters P, De Bus L, Nelis HJ, Depuydt P, Coenye T. Assessment of microbial diversity in biofilms recovered from endotracheal tubes using culture dependent and independent approaches. PLoS One. 2012; 7:e38401.

[43] Liu Z, Shi X, Pan F. Species-specific diagnostic marker for rapid identification of Staphylococcus aureus. Diagn Microbiol Infect Dis. 2007; 59:379-82.

[44] Lavenir R, Jocktane D, Laurent F, Nazaret S, Cournoyer B. Improved reliability of Pseudomonas aeruginosa PCR detection by the use of the species-specific ecfX gene target. J Microbiol Meth 2007; 70:20-9.

[45] Perry-O'Keefe H, Rigby S, Oliveira K, Sørensen D, Stender H, Coull J, Hyldig-Nielsen JJ. Identification of indicator microorganisms using a standardized PNA FISH method. J Microbiol Methods. 2001; 47:281-92.

[46] Sundar KM, Nielsen D, Sperry P. Comparison of ventilator-associated pneumonia (VAP) rates between different ICUs: Implications of a zero VAP rate. J Crit Care 2012; 27:26-32.

[47] Al-Tawfiq JA, Abed MS. Decreasing ventilator-associated pneumonia in adult intensive care units using the Institute for Healthcare Improvement bundle. Am J Infect Control 2010; 38:552-6.

[48] Heck K. Decreasing ventilator-associated pneumonia in the intensive care unit: a sustainable comprehensive quality improvement program. Am J Infect Control $2012 ; 40: 877-9$. 
[49] Dennesen $P$, van der Ven A, Vlasveld M, Lokker L, Ramsay G, Kessels $A$, van den Keijbus $P$, van Nieuw Amerongen A, Veerman $E$. Inadequate salivary flow and poor oral mucosal status in intubated intensive care unit patients. Crit Care Med 2003; 31:781-6.

[50] Marsh PD. Controlling the oral biofilm with antimicrobials. J Dent 2010; 38 Suppl 1:S11-5.

[51] Tada A, Hanada N. Opportunistic respiratory pathogens in the oral cavity of the elderly. FEMS Immunol Med Microbiol 2010; 60:1-17.

[52] Wade WG. The oral microbiome in health and disease. Pharmacol Res 2013; 69:137-43.

[53] Wise MP, Cole JM, Williams DW, Lewis MA, Frost PJ. Efficacy of oral chlorhexidine in critical care. Crit Care 2008;12:419.

[54] Doré $P$, Robert R, Grollier G, Rouffineau J, Lanquetot $H$, Charrière JM, Fauchère $\mathrm{JL}$. Incidence of anaerobes in ventilator-associated pneumonia with use of a protected specimen brush. Am $J$ Respir Crit Care Med 1996;153:1292-8.

[55] Brennan MT, Bahrani-Mougeot F, Fox PC, Kennedy TP, Hopkins S, Boucher RC, Lockhart PB. The role of oral microbial colonization in ventilatorassociated pneumonia. Oral Surg Oral Med Oral Pathol Oral Radiol Endod. 2004; 98:665-72.

[56] Carrilho-Neto A, De Paula Ramos S, Sant'ana AC, Passanezi E. Oral health status among hospitalized patients. Int J Dent Hyg 2011; 9:21-9.

[57] Eddens T, Kolls JK. Host defenses against bacterial lower respiratory tract infection. Curr Opin Immunol 2012; 24:424-30. 
[58] Hunter JD. Ventilator associated pneumonia. Postgrad Med J 2006; 82:172-8.

[59] Jones DJ, Munro CL, Grap MJ. Natural history of dental plaque accumulation in mechanically ventilated adults: a descriptive correlational study. Intensive Crit Care Nurs 2011; 27:299-304.

[60] Wood SR, Kirkham J, Shore RC, Brookes SJ, Robinson C. Changes in the structure and density of oral plaque biofilms with increasing plaque age. FEMS Microbiol Ecol 2002; 39:239-44. 


\begin{tabular}{|c|c|c|c|c|}
\hline Species & $\begin{array}{c}\text { Target } \\
\text { Gene }\end{array}$ & Primers & $\begin{array}{c}\text { Amplicon } \\
\text { size }\end{array}$ & Reference \\
\hline S aureus & Vick & $\begin{array}{c}\text { vicK1: 5'-CTA ATA CTG AAA } \\
\text { GTG AGA AAC GTA-3' } \\
\text { vicK2: 5'-TCC TGC ACA } \\
\text { ATC GTA CTA AA-3' }\end{array}$ & $289 \mathrm{bp}$ & 32 \\
\hline P. aeruginosa & ecfX & $\begin{array}{c}\text { Ps.aeru_ECF1: 5'-ATG GAT } \\
\text { GAG CGC TTC CGT G -3' } \\
\text { Ps.aeru_ECF2: 5'-TCA TCC } \\
\text { TTC GCC TCC CTG -3' }\end{array}$ & $528 \mathrm{bp}$ & 33 \\
\hline
\end{tabular}

Table 1 - PCR primers for identification of $S$. aureus and $P$. aeruginosa.

\begin{tabular}{|c|c|c|c|}
\hline Probe & $\begin{array}{c}\text { Nucleotide sequence } \\
\left(5^{\prime}-3^{\prime}\right)\end{array}$ & $\begin{array}{c}\text { Fluorescent } \\
\text { marker (N- } \\
\text { terminal) }\end{array}$ & $\begin{array}{c}\text { final probe } \\
\text { concentration } \\
(\mathrm{nM})\end{array}$ \\
\hline $\begin{array}{c}\text { Bacterial } \\
\text { Universal }\end{array}$ & CTGCCTCCCGTAGGA & Cy3-00- & 300 \\
\hline $\begin{array}{c}\text { Pseudomonas } \\
\text { aeruginosa }\end{array}$ & AACTTGCTGAACCAC & FITC-00- & 300 \\
\hline $\begin{array}{c}\text { Staphylococcus } \\
\text { aureus }\end{array}$ & GCTTCTCGTCCGTTC & Cy5-00- & 450 \\
\hline $\begin{array}{c}\text { Candida } \\
\text { albicans }\end{array}$ & ACAGCAGAAGCCGTG & FITC-00- & 300 \\
\hline
\end{tabular}

Table 2 - Species-specific PNA probes and associated fluorescent labels 


\begin{tabular}{|c|c|c|c|c|c|c|}
\hline Recruited patients & Patient NO. & Gender & Age & Admission details (reason for MV) & DFMT & Antibiotic use \\
\hline 1 & PN001 & M & 51 & Respiratory failure & 8 & Clindomicin, Meropenem \\
\hline 2 & PN002 & M & 33 & Stroke/brain injury/seizures & 4 & - \\
\hline 3 & PN003 & $M$ & 31 & Overdose/suicide attempt & 9 & Co-amoxiclav \\
\hline 4 & PN004 & $\mathrm{F}$ & 55 & Stroke/brain injury/seizures & 19 & Cefuroxime \\
\hline 5 & PN005 & $M$ & 62 & Stroke/brain injury/seizures & 21 & Cefuxome (in theatre) \\
\hline 6 & PN006 & $\mathrm{F}$ & 34 & Respiratory failure & 0 & Meropenem, Gentimicin, Co-tremoxyle \\
\hline 7 & PN007 & $\mathrm{F}$ & 54 & Stroke/brain injury/seizures & 11 & Cefuroxime \\
\hline 8 & PN008 & M & 63 & Respiratory failure & 12 & Clarthromycin, co-amoxiclav \\
\hline 9 & PN009 & $\mathrm{F}$ & 77 & Other & 23 & Meropenem, Tazocin \\
\hline 10 & PN010 & $\mathrm{F}$ & 30 & Stroke/brain injury/seizures & - & Trimethroprim \\
\hline 11 & PN011 & $\mathrm{F}$ & 73 & Respiratory failure & 16 & Augmentin Tazocin, Clarithromycin \\
\hline 12 & PN012 & M & 68 & Respiratory failure & 13 & Tazocin \\
\hline 13 & PN013 & $\mathrm{F}$ & 50 & Stroke/brain injury/seizures & 14 & - \\
\hline 14 & PN014 & M & 44 & Respiratory failure & 11 & Meropenem, Tazocin \\
\hline 15 & PN015 & $\mathrm{F}$ & 49 & Stroke/brain injury/seizures & 11 & Cefuroxime \\
\hline 16 & PN016 & M & 28 & Other & 4 & Clindomicin, Meropenem \\
\hline 17 & PN017 & $\mathrm{F}$ & 51 & $\mathrm{OOHCA}$ & 23 & - \\
\hline 18 & PN018 & M & 39 & Overdose/suicide attempt & - & - \\
\hline 19 & PN019 & M & 69 & Poly-trauma & 22 & Teicopleinin, Cefuroxime, Tobramycin, Erythromycin \\
\hline 20 & PN020 & $\mathrm{F}$ & 29 & Poly-trauma & 3 & Tazocin, \\
\hline 21 & PN021 & $\mathrm{F}$ & 18 & Stroke/brain injury/seizures & 0 & Aciclovir \\
\hline 22 & PN022 & M & 72 & $\mathrm{OOHCA}$ & 12 & Tazocin \\
\hline 23 & PN023 & M & 19 & Stroke/brain injury/seizures & 5 & Tazocin, Clarithomycin \\
\hline 24 & PN024 & M & 40 & Stroke/brain injury/seizures & 14 & - \\
\hline
\end{tabular}




$\begin{array}{llll}25 & \text { PN025 } & \text { F } & 27 \\ 26 & \text { PN026 } & \text { F } & 63 \\ 27 & \text { PN027 } & \text { M } & 41 \\ 28 & \text { PN028 } & \text { F } & 55 \\ 29 & \text { PN029 } & \text { M } & 76 \\ 30 & \text { PN030 } & \text { F } & 58 \\ 31 & \text { PN031 } & \text { F } & 31 \\ 32 & \text { PN032 } & \text { M } & 67 \\ 33 & \text { PN033 } & \text { F } & 85 \\ 34 & \text { PN034 } & \text { M } & 57 \\ 35 & \text { PN035 } & \text { M } & 58 \\ 36 & \text { PN036 } & \text { M } & 60 \\ 37 & \text { PN037 } & \text { M } & 37 \\ 38 & \text { PN038 } & \text { M } & 37 \\ 39 & \text { PN039 } & \text { F } & 86 \\ 40 & \text { PN040 } & \text { F } & 60 \\ 41 & \text { PN041 } & \text { F } & 58 \\ 42 & \text { PN042 } & \text { M } & 74 \\ 43 & \text { PN043 } & \text { M } & 59 \\ 44 & \text { PN045 } & \text { F } & 22 \\ 45 & \text { PN046 } & \text { M } & 48 \\ 46 & \text { PN047 } & \text { M } & 53 \\ 47 & \text { PN048 } & \text { M } & 57 \\ 48 & \text { PN049 } & \text { F } & 75 \\ 50 & \text { PN050 } & \text { M } & 39 \\ 51 & \text { PN051 } & \text { F } & 73 \\ & \text { PN052 } & \text { M } & 65\end{array}$

Stroke/brain injury/seizures General surgery - Stomach Stroke/brain injury/seizures

Respiratory failure

Respiratory failure

Stroke/brain injury/seizures

Other

Stroke/brain injury/seizures

Respiratory failure

Other

OOHCA

OOHCA

Stroke/brain injury/seizures

Stroke/brain injury/seizures

Respiratory failure

Respiratory failure

Respiratory failure

Stroke/brain injury/seizures

Stroke/brain injury/seizures

Stroke/brain injury/seizures OOHCA

Stroke/brain injury/seizures Stroke/brain injury/seizures General surgery - Stomach Stroke/brain injury/seizures Stroke/brain injury/seizures Other
4

15

15

17

\author{
Meropenem \\ - \\ Co-amoxiclav, Tazocin
}

Ciprofloxacin, Metronizadole, Gentamycin

Meropenem,

Augmentin, Tazocin, Clarithromycin

Amoxicillin, Co-amoxiclav, Clarithromycin, Tazocin

Cefuroxime, Metronidazole, Ciprofloxacin, Gentamycin

Tazocin

Ceftrixone, Meropenem, Ciprofloxacin

Meropenem, Ciprofloxacin, Ceftriaxome

Co-amoxiclav, Tazocin, Clarithromycin

Tazocin

$-$

Cefuroxime

Gentamycin, Tazocin

Cefalexin, Meropenem 


$\begin{array}{llll}52 & \text { PN053 } & \text { F } & 66 \\ 53 & \text { PN054 } & \text { M } & 66 \\ 54 & \text { PN055 } & \text { F } & 60 \\ 55 & \text { PN056 } & \text { F } & 49 \\ 56 & \text { PN057 } & \text { M } & 53 \\ 57 & \text { PN058 } & \text { F } & 38 \\ 58 & \text { PN059 } & \text { M } & 86 \\ 59 & \text { PN060 } & \text { M } & 39 \\ 60 & \text { PN061 } & \text { M } & 36 \\ 61 & \text { PN062 } & \text { M } & 21 \\ 62 & \text { PN063 } & \text { M } & 58 \\ 63 & \text { PN064 } & \text { M } & 44 \\ 64 & \text { PN065 } & \text { F } & 42 \\ 65 & \text { PN066 } & \text { F } & 73 \\ 66 & \text { PN067 } & \text { M } & 68 \\ 67 & \text { PN068 } & \text { M } & 52 \\ 68 & \text { PN069 } & \text { F } & 82 \\ 69 & \text { PN070 } & \text { M } & 18 \\ 70 & \text { PN071 } & \text { M } & 26 \\ 71 & \text { PN072 } & \text { M } & 67 \\ 72 & \text { PN073 } & \text { M } & 59 \\ 73 & \text { PN074 } & \text { F } & 51 \\ 74 & \text { PN075 } & \text { M } & 75 \\ 75 & \text { PN076 } & \text { M } & 49 \\ 76 & \text { PN077 } & \text { M } & 70 \\ 77 & \text { PN078 } & \text { M } & 75 \\ 78 & \text { PN079 } & \text { F } & 51\end{array}$

$\begin{array}{cc}\text { Respiratory failure } & 11 \\ \text { Other } & 13 \\ \text { Other } & 8 \\ \text { Stroke/brain injury/seizures } & 17 \\ \text { Respiratory failure } & 11 \\ \text { Stroke/brain injury/seizures } & 6 \\ \text { General surgery - Stomach } & 28 \\ \text { Stroke/brain injury/seizures } & 9 \\ \text { Poly-trauma } & 14 \\ \text { Poly-trauma } & 1 \\ \text { Respiratory failure } & - \\ \text { OOHCA } & 23 \\ \text { General surgery - Stomach } & 13 \\ \text { Respiratory failure } & 0 \\ \text { Respiratory failure } & 19 \\ \text { OOHCA } & 8 \\ \text { General surgery - Stomach } & 20 \\ \text { Poly-trauma } & 2 \\ \text { Poly-trauma } & 7 \\ \text { Respiratory failure } & 10 \\ \text { Other } & 19 \\ \text { Stroke/brain injury/seizures } & 17 \\ \text { Stroke/brain injury/seizures } & 20 \\ \text { Respiratory failure } & 16 \\ \text { Stroke/brain injury/seizures } & 18 \\ \text { Respiratory failure } & 24 \\ \text { Respiratory failure } & -\end{array}$

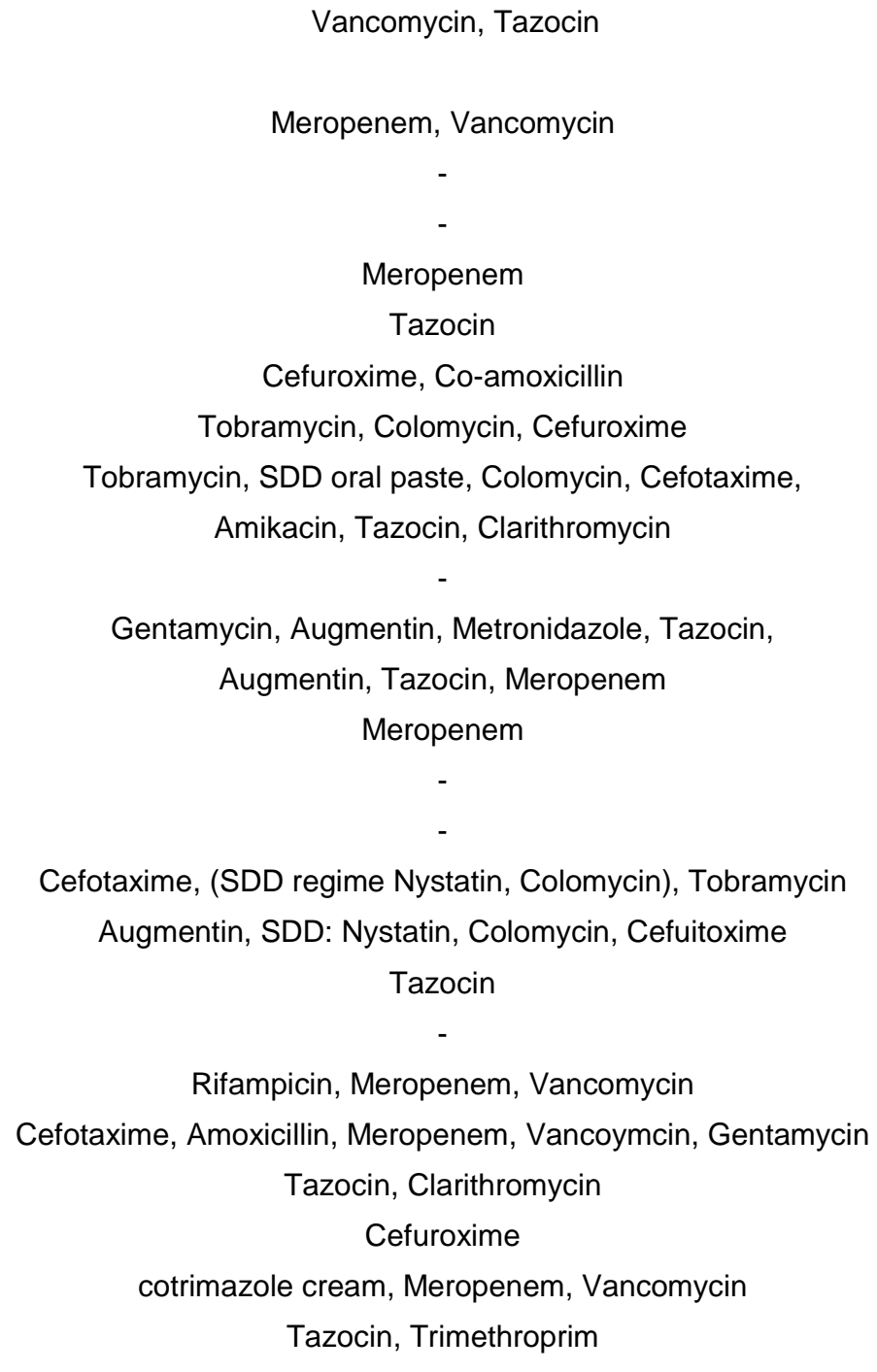




$\begin{array}{llcl}79 & \text { PN080 } & \text { F } & 71 \\ 80 & \text { PN081 } & \text { M } & 74 \\ 81 & \text { PN082 } & \text { F } & 45 \\ 82 & \text { PN083 } & \text { M } & 47 \\ 83 & \text { PN084 } & \text { M } & 58 \\ 84 & \text { PN085 } & \text { F } & 75 \\ 85 & \text { PN086 } & \text { M } & 74 \\ 86 & \text { PN087 } & \text { M } & 80 \\ 87 & \text { PN088 } & \text { F } & 40 \\ 88 & \text { PN089 } & \text { M } & 38 \\ 89 & \text { PN090 } & \text { M } & 66 \\ 90 & \text { PN092 } & \text { M } & 55 \\ 91 & \text { PN093 } & \text { F } & 42 \\ 92 & \text { PN094 } & \text { M } & 60 \\ 93 & \text { PN095 } & \text { M } & 41 \\ 94 & \text { PN096 } & \text { F } & 27 \\ 95 & \text { PN097 } & \text { F } & 77 \\ 96 & \text { PN099 } & \text { M } & 58 \\ 97 & \text { PN100 } & \text { M } & 26 \\ 98 & \text { PN101 } & \text { M } & 29 \\ 99 & \text { PN102 } & \text { M } & 30 \\ 100 & \text { PN103 } & \text { F } & 80 \\ 101 & \text { PN104 } & \text { M } & 56 \\ 102 & \text { PN105 } & \text { M } & 67 \\ 103 & \text { PN106 } & \text { F } & 60 \\ 104 & \text { PN107 } & \text { F } & 47 \\ 105 & \text { PN108 } & \text { M } & 74\end{array}$

$\begin{array}{cc}\text { Respiratory failure } & 6 \\ \text { Other } & 18 \\ \text { Stroke/brain injury/seizures } & 1 \\ \text { Respiratory failure } & 1 \\ \text { Poly-trauma } & 17 \\ \text { Respiratory failure } & 14 \\ \text { Stroke/brain injury/seizures } & 5 \\ \text { OOHCA } & 11 \\ \text { Dental/Oral cavity } & 22 \\ \text { Poly-trauma } & 15 \\ \text { Respiratory failure } & 17 \\ \text { Stroke/brain injury/seizures } & 13 \\ \text { Stroke/brain injury/seizures } & 7 \\ \text { Respiratory failure } & 13 \\ \text { Stroke/brain injury/seizures } & 9 \\ \text { Other } & 1 \\ \text { Poly-trauma } & 22 \\ \text { Other } & 9 \\ \text { Overdose/suicide attempt } & 6 \\ \text { Respiratory failure } & 25 \\ \text { Respiratory failure } & 8 \\ \text { Respiratory failure } & - \\ \text { OOHCA } & 18 \\ \text { OOHCA } & 14 \\ \text { Respiratory failure } & 19 \\ \text { Stroke/brain injury/seizures } & 12 \\ \text { OOHCA } & - \\ \end{array}$

Meropenem
Tazocin
Gentamicin
Augmentin, Clarithromycin
Augmentin, SDD: Colomycin and Tobramycin, Teicoplanin
Meropenem
Co-amoxiclav, Tobramycin, (SDD: Colistin + Nystatin)
Tazocin, Co-trimoxizole
Tazocin
Meropenem, Ceftriaxone, Rifampicin, Vancomycin
Co-amoxiclav, Clarithromycin
-
Amoxicillin, Ceftriaxone
Colomycin, Tobramycin, Cefotaxime
Rifampicin, Isoniazid, Pyrazinamide, Ethambutol
Clarythromcin, Cefotaxime
Meropenem
Co-amoxiclav, Clarithromycin, Co-trimoxazole
Augmentin, Co-amoxiclav, Clarithryomcin
-
-
Amoxicilin
-
-


Tazocin

Metronidazole, Cefotaxime

Table 3 - Patient demographics: age, gender, DMFT scores, admission details (primary reason for mechanical ventilation) and antibiotic administration 


\begin{tabular}{ccccccc} 
& \multicolumn{5}{c}{ 114 Isolates of S. aureus } \\
\cline { 2 - 7 } & Cefepime & Cefoxitin & Ceftazidime & $\begin{array}{c}\text { Fusidic } \\
\text { Acid }\end{array}$ & Gentamicin & Meropenem \\
\hline Sensitive \% & 65 & 88 & 88 & 89 & 82 & 86 \\
Intermediate \% & 20 & 0 & 2 & 4 & 13 & 6 \\
Resistant \% & 15 & 12 & 11 & 7 & 4 & 8 \\
& & & & & & \\
Sensitive \% & Ciprofloxacin & Clindamycin & Erythromycin & Penicillin & Tobramycin & Vancomycin \\
\cline { 2 - 7 } Intermediate \% & 86 & 61 & 62 & 55 & 79 & 88 \\
Resistant \% & 4 & 27 & 16 & 31 & 15 & 1 \\
\hline
\end{tabular}

Table 4 - Antimicrobial sensitivities for S. aureus isolates

\begin{tabular}{lccccccc} 
& \multicolumn{7}{c}{56 Isolates of $P$. aeruginosa } \\
\cline { 2 - 7 } & Ceftazidime & Ciprofloxacin & Gentamicin & Meropenem & Piperacillin & Piperacillin-Tazobactam & Tobramycin \\
\hline Resistant \% & 8.8 & 1.8 & 1.8 & 22.8 & 15.8 & 10.5 & 1.8 \\
Sensitive \% & 82.5 & 87.7 & 66.7 & 64.9 & 40.4 & 63.2 & 96.5 \\
Intermediate \% & 8.8 & 10.5 & 31.6 & 12.3 & 43.9 & 26.3 & 1.8 \\
\hline
\end{tabular}

Table 5 - Antimicrobial sensitivities for $P$. aeruginosa isolates 


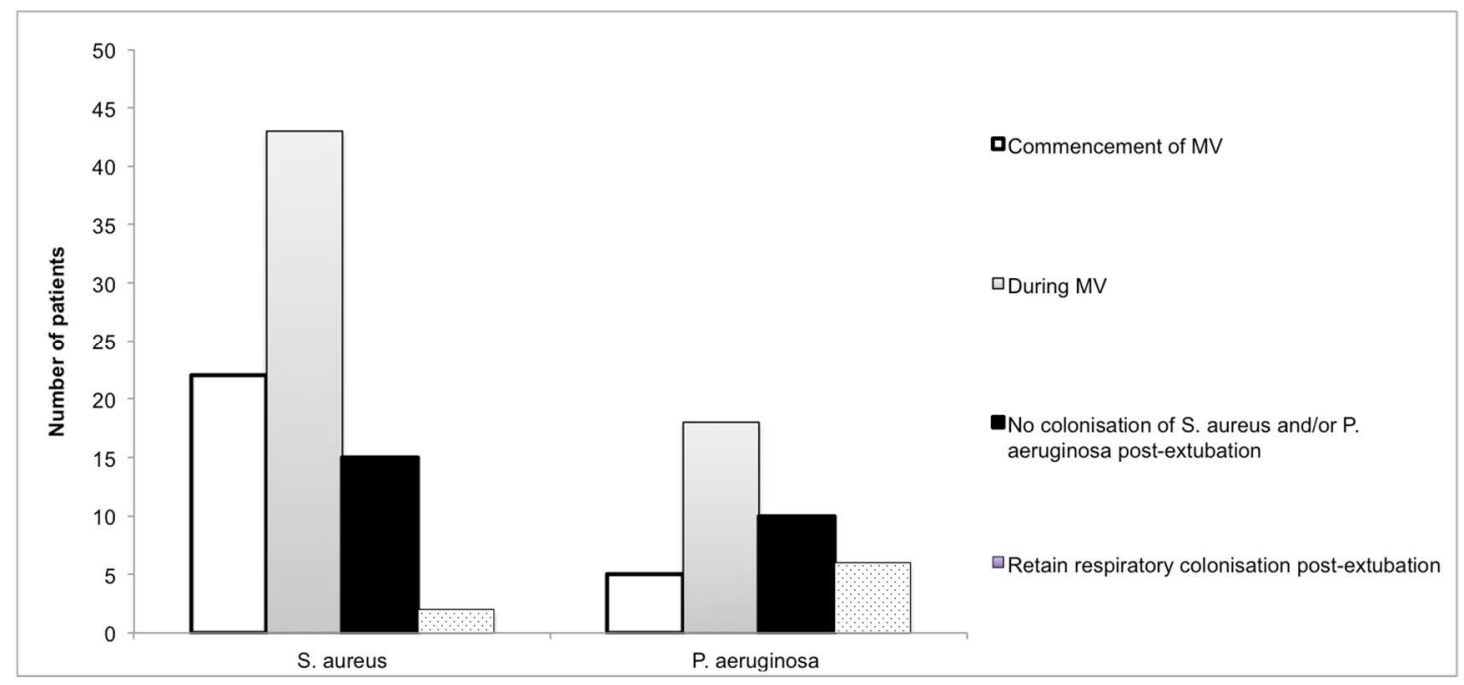

Figure 1 - Microbial colonisation of respiratory pathogens during endotracheal intubation and analysis during the recovery period (up to 8 weeks post ETTextubation). 


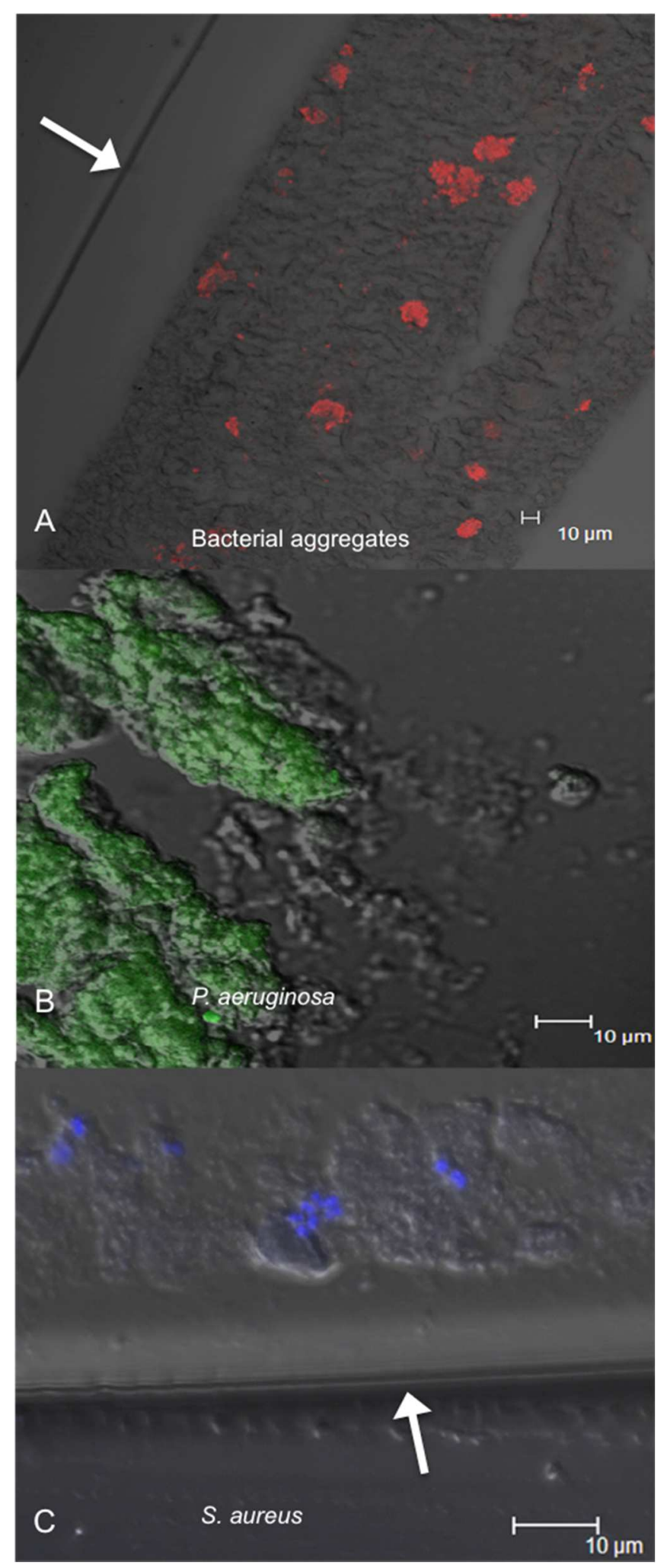

Figure 2 - Micrographs of endotracheal tube (ETT) biofilm obtained by confocal laser scanning microscopy (CLSM). All micrographs show a confocal fluorescence image superimposed (colour) upon a Nomarski differential interference (greyscale) A) Aggregates of bacteria hybridised with the universal bacterial Peptide Nucleic Acid (PNA) probe labeled with Cy-3 
(red); B) Pseudomonas aeruginosa hybridised with species specific FITC labelled PNA probe (green); C) Staphylococcus aureus hybridised with species specific PNA probe conjugated with Cy-5 (blue). Where possible, the edge of the ETT section is arrowed. 


\begin{tabular}{|c|c|c|c|c|c|c|c|c|c|c|c|c|c|}
\hline \multicolumn{2}{|c|}{ Patient } & \multicolumn{12}{|c|}{ Antibiotic } \\
\hline Patient & Sample & Cefepime & Cefoxitin & Ceftazidime & Ciprofloxacin & Clindamycin & Erythromycin & $\begin{array}{l}\text { Fusidic } \\
\text { Acid }\end{array}$ & Gentamicin & Meropenem & Penicillin & Tobramycin & Vancomycin \\
\hline PN004 & SUB & 25 & 0 & 20 & 35 & 0 & 0 & 0 & 26 & 26 & 0 & 22 & 0 \\
\hline PN005 & $\mathrm{DP}$ & 28 & 29 & 16 & 28 & 0 & 0 & 30 & 24 & 34 & 16 & 22 & 16 \\
\hline PN005 & DP & 27 & 29 & 19 & 28 & 0 & 0 & 36 & 24 & 38 & 17 & 23 & 16 \\
\hline PN007 & DP & 27 & 30 & 20 & 20 & 27 & 26 & 30 & 22 & 34 & 40 & 22 & 17 \\
\hline PN007 & DP & 28 & 29 & 18 & 21 & 36 & 25 & 36 & 22 & 36 & 16 & 22 & 16 \\
\hline PN007 & DP & 24 & 28 & 18 & 21 & 22 & 26 & 31 & 24 & 32 & 29 & 21 & 16 \\
\hline PN007 & DP & 27 & 0 & 28 & 35 & 0 & 0 & 24 & 23 & 35 & 0 & 22 & 0 \\
\hline PN009 & $\mathrm{DP}$ & 24 & 29 & 18 & 27 & 20 & 24 & 33 & 23 & 36 & 42 & 20 & 18 \\
\hline PN009 & NBL & 22 & 28 & 17 & 24 & 30 & 24 & 33 & 23 & 33 & 33 & 23 & 16 \\
\hline PN009 & $\mathrm{DP}$ & 23 & 29 & 16 & 22 & 30 & 18 & 32 & 22 & 31 & 28 & 22 & 16 \\
\hline PN015 & $\mathrm{DP}$ & 28 & 0 & 27 & 35 & 0 & 0 & 0 & 23 & 36 & 0 & 25 & 0 \\
\hline PN021 & ETT & 26 & 31 & 14 & 21 & 29 & 21 & 35 & 24 & 36 & 17 & 21 & 16 \\
\hline PN021 & DP & 27 & 29 & 17 & 20 & 30 & 24 & 36 & 23 & 39 & 16 & 19 & 16 \\
\hline PN021 & NBL & 28 & 30 & 18 & 20 & 30 & 25 & 35 & 22 & 36 & 15 & 23 & 16 \\
\hline PN021 & $\mathrm{DP}$ & 24 & 29 & 17 & 22 & 28 & 21 & 30 & 22 & 32 & 29 & 21 & 17 \\
\hline PN024 & SUB & 26 & 30 & 19 & 21 & 28 & 26 & 30 & 23 & 31 & 15 & 21 & 16 \\
\hline PN024 & NBL & 25 & 29 & 19 & 22 & 27 & 26 & 30 & 22 & 30 & 17 & 22 & 16 \\
\hline PN024 & ETT & 24 & 29 & 18 & 22 & 27 & 23 & 29 & 23 & 33 & 30 & 22 & 18 \\
\hline PN024 & DP & 23 & 30 & 19 & 26 & 30 & 23 & 31 & 22 & 30 & 39 & 20 & 18 \\
\hline PN024 & NBL & 27 & 28 & 16 & 28 & 29 & 22 & 32 & 23 & 33 & 36 & 21 & 19 \\
\hline PN025 & $\mathrm{DP}$ & 25 & 30 & 17 & 27 & 28 & 24 & 30 & 23 & 32 & 30 & 21 & 16 \\
\hline PN025 & NBL & 27 & 30 & 18 & 28 & 30 & 24 & 31 & 22 & 31 & 34 & 22 & 17 \\
\hline
\end{tabular}




\begin{tabular}{|c|c|c|c|c|c|c|c|c|c|c|c|c|c|}
\hline PN025 & NBL & 27 & 29 & 17 & 27 & 28 & 25 & 30 & 22 & 30 & 40 & 22 & 16 \\
\hline PN025 & ETT & 26 & 29 & 18 & 26 & 27 & 25 & 32 & 23 & 32 & 29 & 21 & 18 \\
\hline PN027 & NBL & 28 & 29 & 28 & 34 & 29 & 23 & 30 & 24 & 31 & 40 & 21 & 17 \\
\hline PN027 & NBL & 25 & 29 & 16 & 0 & 29 & 24 & 30 & 22 & 30 & 30 & 23 & 17 \\
\hline PN027 & ETT & 23 & 30 & 18 & 0 & 22 & 0 & 30 & 22 & 10 & 0 & 21 & 17 \\
\hline PN028 & ETT & 0 & 9 & 0 & 24 & 23 & 0 & 30 & 25 & 0 & 0 & 19 & 14 \\
\hline PN028 & SUB & 0 & 10 & 0 & 12 & 29 & 0 & 33 & 22 & 13 & 7 & 22 & 16 \\
\hline PN028 & NBL & 0 & 11 & 0 & 0 & 31 & 0 & 30 & 22 & 12 & 0 & 22 & 17 \\
\hline PN037 & $\mathrm{DP}$ & 24 & 30 & 18 & 26 & 28 & 18 & 31 & 25 & 30 & 17 & 20 & 18 \\
\hline PN037 & NBL & 25 & 30 & 19 & 27 & 24 & 27 & 30 & 23 & 30 & 17 & 21 & 17 \\
\hline PN037 & NBL & 31 & 30 & 20 & 25 & 28 & 26 & 30 & 24 & 30 & 19 & 19 & 18 \\
\hline PN037 & NBL & 24 & 30 & 17 & 24 & 28 & 22 & 30 & 24 & 30 & 20 & 20 & 20 \\
\hline PN042 & $\mathrm{DP}$ & 24 & 30 & 18 & 24 & 28 & 23 & 30 & 24 & 30 & 20 & 20 & 20 \\
\hline PN042 & NBL & 24 & 30 & 18 & 25 & 24 & 23 & 30 & 24 & 30 & 20 & 19 & 18 \\
\hline PN042 & SUB & 16 & 0 & 0 & 25 & 13 & 26 & 30 & 24 & 18 & 0 & 14 & 15 \\
\hline PN042 & ETT & 24 & 30 & 18 & 25 & 28 & 22 & 30 & 22 & 30 & 30 & 19 & 19 \\
\hline PN043 & $\mathrm{DP}$ & 24 & 30 & 18 & 24 & 28 & 22 & 30 & 24 & 30 & 18 & 18 & 18 \\
\hline PN045 & DP & 22 & 29 & 19 & 23 & 30 & 23 & 30 & 22 & 32 & 21 & 22 & 19 \\
\hline PN046 & $\mathrm{DP}$ & 24 & 30 & 18 & 25 & 28 & 22 & 30 & 22 & 30 & 28 & 19 & 19 \\
\hline PN046 & NBL & 24 & 30 & 18 & 25 & 28 & 22 & 30 & 22 & 30 & 28 & 19 & 19 \\
\hline PN046 & $\mathrm{DP}$ & 25 & 30 & 19 & 24 & 28 & 22 & 30 & 22 & 30 & 28 & 18 & 14 \\
\hline PN046 & NBL & 27 & 30 & 20 & 27 & 25 & 19 & 29 & 22 & 29 & 21 & 22 & 18 \\
\hline PN046 & ETT & 24 & 30 & 18 & 24 & 28 & 22 & 28 & 23 & 30 & 28 & 18 & 21 \\
\hline PN046 & $\mathrm{DP}$ & 22 & 30 & 20 & 23 & 30 & 22 & 29 & 0 & 31 & 18 & 20 & 18 \\
\hline PN048 & NBL & 25 & 30 & 18 & 24 & 24 & 18 & 30 & 22 & 30 & 28 & 20 & 20 \\
\hline PN049 & $\mathrm{DP}$ & 22 & 30 & 19 & 25 & 21 & 20 & 30 & 19 & 29 & 19 & 22 & 20 \\
\hline PN049 & NBL & 20 & 30 & 20 & 24 & 21 & 23 & 29 & 25 & 32 & 29 & 24 & 0 \\
\hline
\end{tabular}




\begin{tabular}{|c|c|c|c|c|c|c|c|c|c|c|c|c|c|}
\hline PN049 & DP & 25 & 0 & 18 & 11 & 10 & 22 & 19 & 20 & 30 & 20 & 14 & 0 \\
\hline PN050 & DP & 22 & 30 & 19 & 25 & 28 & 20 & 30 & 22 & 30 & 28 & 19 & 20 \\
\hline PN050 & NBL & 22 & 29 & 20 & 24 & 28 & 19 & 29 & 19 & 30 & 19 & 20 & 20 \\
\hline PN050 & ETT & 23 & 30 & 20 & 22 & 29 & 19 & 29 & 23 & 30 & 28 & 20 & 20 \\
\hline PN051 & $\mathrm{DP}$ & 23 & 30 & 19 & 0 & 28 & 0 & 29 & 19 & 30 & 28 & 24 & 20 \\
\hline PN051 & DP & 20 & 30 & 20 & 22 & 21 & 19 & 30 & 22 & 29 & 22 & 24 & 21 \\
\hline PN052 & DP & 24 & 31 & 18 & 24 & 0 & 0 & 29 & 22 & 30 & 28 & 22 & 19 \\
\hline PN052 & NBL & 23 & 30 & 19 & 24 & 30 & 23 & 29 & 22 & 30 & 29 & 21 & 4 \\
\hline PN052 & ETT & 21 & 30 & 19 & 22 & 21 & 22 & 29 & 22 & 30 & 20 & 20 & 11 \\
\hline PN054 & NBL & 23 & 30 & 20 & 24 & 22 & 23 & 30 & 22 & 30 & 21 & 19 & 19 \\
\hline PN056 & $\mathrm{DP}$ & 23 & 30 & 20 & 22 & 29 & 19 & 29 & 22 & 30 & 19 & 22 & 19 \\
\hline PN056 & NBL & 23 & 30 & 20 & 22 & 29 & 19 & 30 & 24 & 30 & 29 & 19 & 21 \\
\hline PN056 & $\mathrm{DP}$ & 19 & 29 & 21 & 22 & 22 & 23 & 30 & 18 & 30 & 29 & 21 & 19 \\
\hline PN056 & NBL & 20 & 30 & 19 & 22 & 29 & 23 & 30 & 24 & 29 & 28 & 21 & 19 \\
\hline PN056 & SUB & 19 & 30 & 21 & 22 & 21 & 23 & 30 & 18 & 30 & 28 & 22 & 20 \\
\hline PN056 & SUB & 19 & 30 & 21 & 23 & 21 & 22 & 30 & 18 & 28 & 21 & 21 & 21 \\
\hline PN057 & NBL & 19 & 29 & 20 & 23 & 22 & 22 & 30 & 22 & 30 & 19 & 21 & 22 \\
\hline PN057 & ETT & 20 & 30 & 18 & 23 & 22 & 19 & 29 & 23 & 30 & 21 & 21 & 21 \\
\hline PN058 & SUB & 19 & 29 & 20 & 21 & 22 & 22 & 29 & 18 & 30 & 30 & 22 & 0 \\
\hline PN063 & NBL & 20 & 29 & 18 & 22 & 22 & 19 & 29 & 18 & 30 & 30 & 22 & 0 \\
\hline PN068 & $\mathrm{DP}$ & 21 & 30 & 20 & 0 & 9 & 0 & 30 & 20 & 30 & 30 & 20 & 0 \\
\hline PN068 & NBL & 22 & 30 & 20 & 22 & 28 & 0 & 26 & 21 & 29 & 28 & 0 & 28 \\
\hline PN068 & $\mathrm{DP}$ & 22 & 30 & 19 & 21 & 28 & 28 & 11 & 21 & 30 & 29 & 21 & 19 \\
\hline PN077 & NBL & 22 & 29 & 19 & 21 & 27 & 22 & 29 & 20 & 21 & 22 & 19 & 19 \\
\hline PN077 & $\mathrm{DP}$ & 22 & 30 & 19 & 26 & 28 & 22 & 30 & 20 & 32 & 23 & 20 & 0 \\
\hline PN077 & NBL & 21 & 30 & 20 & 22 & 28 & 22 & 30 & 20 & 30 & 29 & 21 & 19 \\
\hline PN080 & SUB & 0 & 14 & 0 & 10 & 28 & 0 & 30 & 10 & 20 & 0 & 10 & 21 \\
\hline
\end{tabular}




\begin{tabular}{|c|c|c|c|c|c|c|c|c|c|c|c|c|c|}
\hline PN080 & DP & 0 & 13 & 0 & 0 & 32 & 0 & 30 & 10 & 21 & 0 & 10 & 21 \\
\hline PN080 & $\mathrm{DP}$ & 0 & 15 & 0 & 0 & 33 & 0 & 33 & 11 & 21 & 0 & 0 & 21 \\
\hline PN081 & NBL & 0 & 0 & 0 & 0 & 28 & 23 & 10 & 27 & 30 & 0 & 20 & 0 \\
\hline PN081 & SUB & 0 & 0 & 0 & 0 & 32 & 26 & 29 & 23 & 7 & 0 & 20 & 9 \\
\hline PN081 & DP & 0 & 9 & 0 & 0 & 33 & 29 & 31 & 24 & 14 & 0 & 23 & 18 \\
\hline PN081 & $\mathrm{DP}$ & 0 & 8 & 0 & 0 & 30 & 27 & 21 & 24 & 9 & 0 & 22 & 17 \\
\hline PN086 & NBL & 23 & 30 & 19 & 23 & 28 & 22 & 29 & 22 & 29 & 21 & 22 & 20 \\
\hline PN087 & ETT & 21 & 30 & 19 & 23 & 28 & 19 & 30 & 24 & 29 & 21 & 24 & 20 \\
\hline PN087 & NBL & 25 & 20 & 16 & 21 & 29 & 8 & 29 & 22 & 29 & 17 & 23 & 20 \\
\hline PN087 & SUB & 24 & 30 & 19 & 24 & 22 & 0 & 30 & 22 & 30 & 28 & 22 & 20 \\
\hline PN087 & $\mathrm{DP}$ & 23 & 30 & 20 & 22 & 28 & 0 & 30 & 22 & 29 & 29 & 21 & 20 \\
\hline PN089 & NBL & 23 & 30 & 20 & 24 & 28 & 22 & 30 & 24 & 30 & 29 & 21 & 19 \\
\hline PN089 & SUB & 23 & 29 & 21 & 22 & 21 & 22 & 29 & 22 & 30 & 28 & 20 & 21 \\
\hline PN089 & NBL & 25 & 30 & 22 & 23 & 28 & 24 & 29 & 23 & 29 & 31 & 20 & 20 \\
\hline PN089 & $\mathrm{DP}$ & 21 & 30 & 21 & 24 & 28 & 22 & 29 & 23 & 29 & 28 & 21 & 19 \\
\hline PN092 & $\mathrm{DP}$ & 23 & 30 & 22 & 0 & 21 & 23 & 30 & 22 & 27 & 24 & 21 & 20 \\
\hline PN092 & NBL & 21 & 30 & 20 & 23 & 21 & 24 & 29 & 23 & 29 & 29 & 22 & 20 \\
\hline PN094 & NBL & 24 & 29 & 21 & 22 & 28 & 23 & 30 & 22 & 29 & 29 & 21 & 19 \\
\hline PN095 & $\mathrm{DP}$ & 21 & 29 & 21 & 22 & 0 & 0 & 29 & 22 & 29 & 32 & 21 & 20 \\
\hline PN095 & NBL & 29 & 32 & 17 & 22 & 0 & 0 & 17 & 25 & 35 & 29 & 22 & 19 \\
\hline PN095 & SUB & 26 & 30 & 14 & 24 & 0 & 0 & 19 & 24 & 33 & 29 & 18 & 18 \\
\hline PN095 & $\mathrm{DP}$ & 22 & 30 & 18 & 24 & 0 & 0 & 19 & 23 & 29 & 18 & 21 & 0 \\
\hline PN097 & NBL & 23 & 30 & 21 & 24 & 24 & 23 & 30 & 21 & 31 & 31 & 22 & 18 \\
\hline PN099 & $\mathrm{DP}$ & 20 & 29 & 23 & 24 & 28 & 22 & 30 & 23 & 30 & 28 & 21 & 21 \\
\hline PN099 & DP & 23 & 30 & 19 & 22 & 27 & 19 & 29 & 23 & 30 & 29 & 21 & 18 \\
\hline PN102 & DP & 23 & 30 & 19 & 23 & 25 & 22 & 29 & 22 & 33 & 29 & 19 & 19 \\
\hline PN102 & DP & 20 & 29 & 22 & 21 & 0 & 0 & 30 & 22 & 34 & 30 & 21 & 20 \\
\hline
\end{tabular}




\begin{tabular}{|c|c|c|c|c|c|c|c|c|c|c|c|c|c|}
\hline PN104 & DP & 21 & 30 & 24 & 23 & 28 & 24 & 30 & 24 & 30 & 21 & 21 & 17 \\
\hline PN104 & NBL & 21 & 30 & 21 & 23 & 21 & 25 & 30 & 24 & 30 & 29 & 22 & 18 \\
\hline PN104 & DP & 20 & 30 & 22 & 24 & 21 & 23 & 30 & 23 & 30 & 28 & 20 & 21 \\
\hline PN105 & NBL & 20 & 30 & 21 & 20 & 28 & 23 & 30 & 23 & 30 & 31 & 22 & 19 \\
\hline PN105 & ETT & 24 & 30 & 22 & 21 & 21 & 24 & 30 & 23 & 29 & 29 & 20 & 18 \\
\hline PN106 & ETT & 22 & 30 & 23 & 21 & 28 & 23 & 29 & 23 & 30 & 30 & 21 & 19 \\
\hline PN108 & $\mathrm{DP}$ & 20 & 30 & 22 & 23 & 21 & 23 & 30 & 23 & 30 & 28 & 19 & 20 \\
\hline PN108 & NBL & 24 & 30 & 19 & 23 & 28 & 22 & 29 & 22 & 29 & 28 & 21 & 20 \\
\hline PN108 & ETT & 21 & 30 & 16 & 23 & 29 & 22 & 31 & 24 & 30 & 28 & 20 & 19 \\
\hline PN109 & $\mathrm{DP}$ & 20 & 30 & 17 & 24 & 24 & 22 & 32 & 22 & 32 & 30 & 20 & 17 \\
\hline PN110 & NBL & 0 & 0 & 0 & 10 & 32 & 0 & 25 & 12 & 0 & 0 & 12 & 20 \\
\hline
\end{tabular}

Supplementary table 1 - Individual antimicrobial sensitivities for $S$. aureus isolates obtained during mechanical, and where possible, into the post- endotracheal tube extubation recovery period.

\begin{tabular}{lc|ccccccc}
\hline \multicolumn{2}{c|}{ Patient } & \multicolumn{7}{c}{ Antibiotics } \\
\hline Patient & Sample & Ceftazidime & Ciprofloxacin & Gentamicin & Meropenem & Piperacillin & Piperacillin-Tazobactam & Tobramycin \\
\hline PN006 & DP & 22 & 30 & 20 & 27 & 24 & 27 & 19 \\
PN007 & DP & 22 & 30 & 20 & 28 & 24 & 27 & 22 \\
PN008 & DP & 24 & 30 & 26 & 28 & 24 & 27 & 21 \\
PN018 & DP & 22 & 30 & 19 & 27 & 24 & 28 & 21 \\
PN018 & NBL & 23 & 30 & 18 & 32 & 25 & 27 & 20 \\
PN030 & DP & 19 & 30 & 19 & 28 & 23 & 27 & 20 \\
PN030 & NBL & 20 & 30 & 19 & 29 & 24 & 27 & 20 \\
PN030 & SUB & 21 & 29 & 20 & 30 & 24 & 27 & 19 \\
PN030 & NBL & 22 & 29 & 20 & 30 & 24 & 29 & 19
\end{tabular}




\begin{tabular}{lc|ccccccc} 
PN030 & ETT & 23 & 30 & 18 & 32 & 20 & 26 & 20 \\
PN030 & DP & 19 & 31 & 19 & 31 & 18 & 26 & 20 \\
PN038 & DP & 22 & 30 & 24 & 0 & 18 & 20 & 20 \\
PN045 & NBL & 22 & 30 & 22 & 0 & 17 & 21 & 22 \\
PN047 & DP & 22 & 29 & 19 & 20 & 21 & 26 & 24 \\
PN047 & DP & 19 & 28 & 21 & 27 & 22 & 29 & 22 \\
PN047 & DP & 22 & 30 & 19 & 27 & 23 & 26 & 19 \\
PN047 & DP & 21 & 30 & 20 & 27 & 19 & 27 & 20 \\
PN048 & NBL & 22 & 30 & 20 & 28 & 23 & 27 & 21 \\
PN049 & DP & 21 & 30 & 19 & 28 & 17 & 18 & 19 \\
PN049 & DP & 22 & 30 & 18 & 18 & 23 & 26 & 21 \\
PN051 & DP & 21 & 30 & 20 & 27 & 23 & 28 & 21 \\
PN060 & DP & 23 & 30 & 21 & 27 & 21 & 25 & 22 \\
PN060 & DP & 22 & 30 & 21 & 18 & 14 & 19 & 21 \\
PN060 & DP & 21 & 30 & 19 & 29 & 21 & 28 & 19 \\
PN062 & DP & 22 & 31 & 21 & 29 & 22 & 27 & 19 \\
PN062 & NBL & 22 & 28 & 21 & 28 & 22 & 27 & 19 \\
PN062 & DP & 22 & 30 & 20 & 0 & 23 & 25 & 20 \\
PN075 & DP & 20 & 30 & 20 & 29 & 21 & 26 & 19 \\
PN078 & NBL & 21 & 30 & 20 & 28 & 20 & 28 & 20 \\
PN079 & SUB & 22 & 30 & 18 & 30 & 21 & 26 & 20 \\
PN079 & DP & 22 & 30 & 21 & 28 & 0 & 14 & 19 \\
PN079 & NBL & 23 & 30 & 21 & 29 & 19 & 28 & 22 \\
PN079 & DP & 22 & 27 & 19 & 6 & 11 & 15 & 21 \\
PN079 & DP & 22 & 27 & 19 & 0 & 12 & 17 & 21 \\
PN081 & DP & 23 & 30 & 20 & 0 & 21 & 27 & 20 \\
PN083 & NBL & 23 & 30 & 21 & 10 & 19 & & 27
\end{tabular}




\begin{tabular}{lc|ccccccc} 
PN095 & SUB & 22 & 29 & 20 & 29 & 20 & 29 & 19 \\
PN095 & DP & 20 & 29 & 21 & 29 & 21 & 28 & 22 \\
PN095 & ETT & 22 & 29 & 21 & 29 & 19 & 29 & 19 \\
PN095 & DP & 22 & 30 & 21 & 0 & 18 & 29 & 18 \\
PN095 & NBL & 21 & 30 & 18 & 10 & 22 & 29 & 19 \\
PN095 & SUB & 21 & 30 & 23 & 28 & 23 & 27 & 20 \\
PN102 & DP & 21 & 30 & 20 & 30 & 24 & 28 & 20 \\
PN104 & DP & 20 & 30 & 19 & 30 & 21 & 28 & 20 \\
PN105 & ETT & 24 & 30 & 19 & 28 & 24 & 27 & 21 \\
PN105 & NBL & 25 & 30 & 19 & 29 & 24 & 29 & 21 \\
PN105 & DP & 21 & 29 & 21 & 29 & 21 & 28 & 21 \\
PN106 & DP & 19 & 29 & 21 & 27 & 23 & 27 & 19 \\
PN107 & DP & 22 & 30 & 21 & 30 & 22 & 28 & 20 \\
PN108 & ETT & 16 & 7 & 17 & 19 & 11 & 19 & 14 \\
PN109 & DP & 20 & 30 & 21 & 31 & 23 & 28 & 20 \\
PN109 & DP & 23 & 30 & 21 & 27 & 23 & 29 & 20 \\
PN109 & DP & 22 & 29 & 21 & 29 & 25 & 28 & 19 \\
PN110 & DP & 22 & 28 & 20 & 28 & 21 & 25 & 20 \\
PN110 & NBL & 23 & 27 & 21 & 28 & 22 & 26 & 19 \\
PN110 & ETT & 22 & 30 & 21 & 29 & 22 & 26 & 21 \\
\hline
\end{tabular}

Supplementary table 2 - Individual antimicrobial sensitivities for $P$. aeruginosa isolates obtained during mechanical, and where possible, into the post- endotracheal tube extubation recovery period. 